\title{
Osgood-Schlatter Lesion Removed Arthroscopically in an Adult Patient
}

George Tsakotos ${ }^{1}$, Dimitrios A. Flevas ${ }^{2}$, Grigorios G. Sasalos ${ }^{2}$, Leonardos Benakis ${ }^{2}$, Anastasios V. Tokis ${ }^{2}$

1. Anatomy, School of Medicine, National and Kapodistrian University of Athens, Athens, GRC 2. Arthroscopy and Orthopaedic Surgery, Metropolitan Hospital, Athens, GRC

Corresponding author: Dimitrios A. Flevas, dflevas@hotmail.com

\begin{abstract}
Osgood-Schlatter disease is a traction apophysitis of the tibial insertion of the patellar tendon. It consists one of the most common causes of knee pain in adolescents and usually presents in young males and it is considered a self-limiting condition. Although the symptoms disappear after the closure of the growth plate in most cases, in some patients they may persist. A variety of conservative treatments are used in most cases, however surgical intervention can be successful for patients who have intolerable symptoms. Most surgical options of the Osgood-Schlatter disease include open procedures, while arthroscopic or direct bursoscopic excision has been reported. We believe that the arthroscopic removal of an unresolved Osgood-Schlatter might be the most appropriate treatment for this condition, and we present a case of a male patient with an ununited ossicle due to an Osgood-Schlatter lesion, which was removed arthroscopically using a multidirectional arthroscope and a motorized semi-hooded barrel burr.
\end{abstract}

Categories: Orthopedics

Keywords: arthroscopy, knee, ununited ossicle, osgood-schlatter disease

\section{Introduction}

Osgood-Schlatter disease was first described in 1903 and is a traction apophysitis of the tibial insertion of the patellar tendon caused by the repetitive strain on the quadriceps femoris muscle [1]. It consists one of the most common causes of knee pain in adolescents and usually presents in young males aged 10 to 14 years, with a bilateral knee ratio of $25 \%$ to $33 \%$. It is a self-limiting condition, with resolution of symptoms in about $90 \%$ of cases with or without some form of conservative treatment and although the symptoms disappear after the closure of the growth plate in most cases, in some patients they may persist [2-5].

Received 03/12/2020 Review began 03/14/2020 Review ended 03/19/2020 Published 03/22/2020

\section{() Copyright 2020}

Tsakotos et al. This is an open access article distributed under the terms of the Creative Commons Attribution License CC-BY 4.0., which permits unrestricted use, distribution, and reproduction in any medium, provided the original author and source are credited.
In most cases conservative treatments, which include rest, lidocaine injection, steroid injection, cylinder casts and infrapatellar straps, are adequate [6]. However, although conservative management has been conventionally favored, surgical intervention can be successful for patients who have intolerable symptoms [7]. Most surgical options of the Osgood-Schlatter disease include open procedures, while arthroscopic or direct bursoscopic excision has been reported $[6,7-11,12,13]$.

Hereby we report a case of a male patient with an ununited ossicle due to an Osgood-Schlatter lesion, which was removed arthroscopically using a multidirectional arthroscope and a motorized semi-hooded barrel burr.

\section{Case Presentation}

A 26-year-old, male semiprofessional soccer player had a prominence of tibial tuberosity for 10 years and reported anterior knee pain during sports activity and while climbing stairs. He claims pain commencement about 15 years ago and since then he mentions occasional pain episodes. He underwent conservative treatment for the last two years with anti-inflammatory drugs and physiotherapy and he had three injections of corticosteroids at different times. On physical examination, there was a permanent tibial tubercle with pain during palpation (Figure 1). Radiographic examination showed an ununited ossicle beneath the patellar tendon (Figure 2). Magnetic resonance imaging sections showed tendinitis on the patellar tendon and an ununited ossicle anterior to the tibial tubercle (Figure 3). Dimensions of the ossicle were $17 \mathrm{~mm} \times 8 \mathrm{~mm}$. 


\section{Cureus}

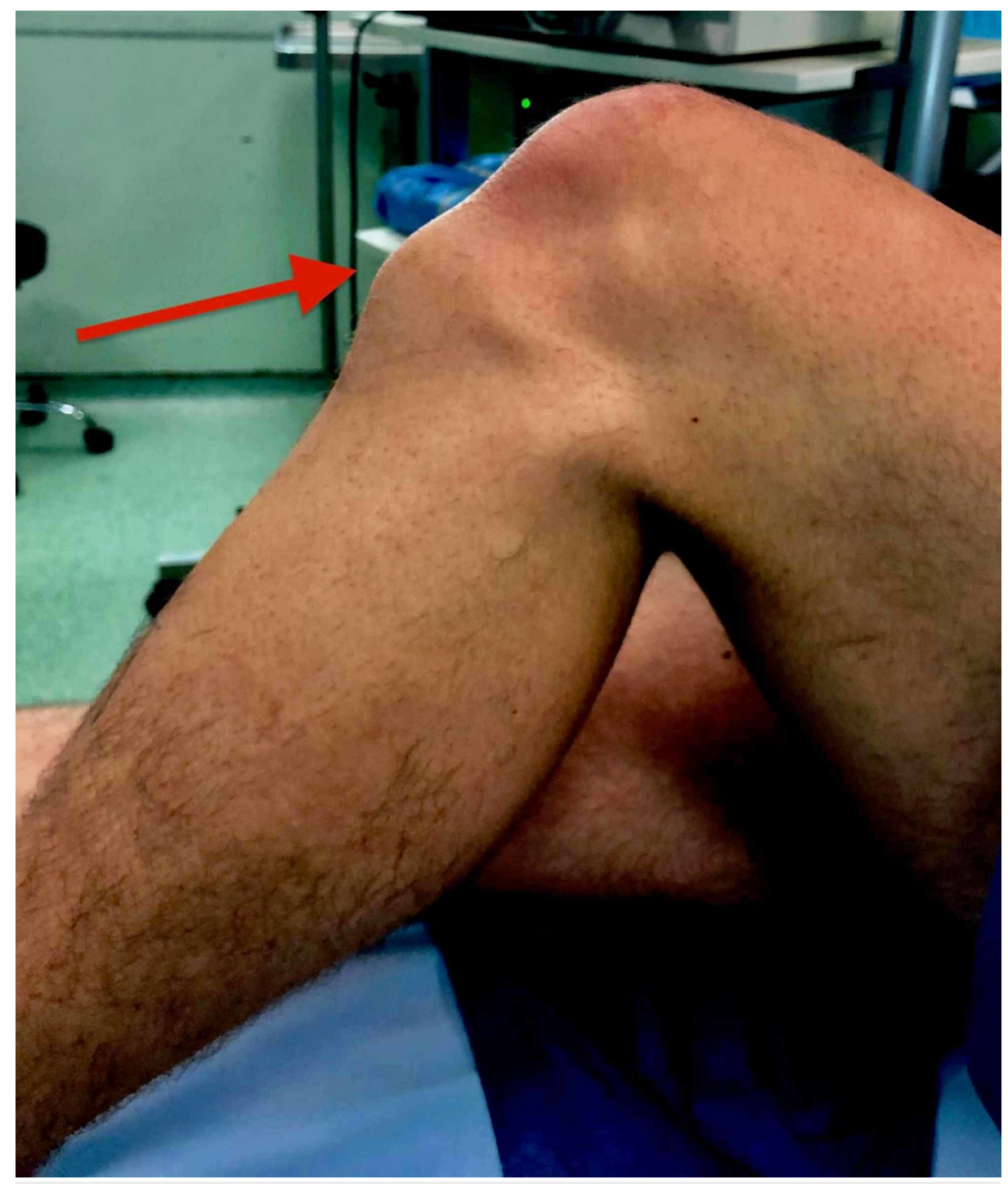

FIGURE 1: The tibial tuberosity prominence. 


\section{Cureus}

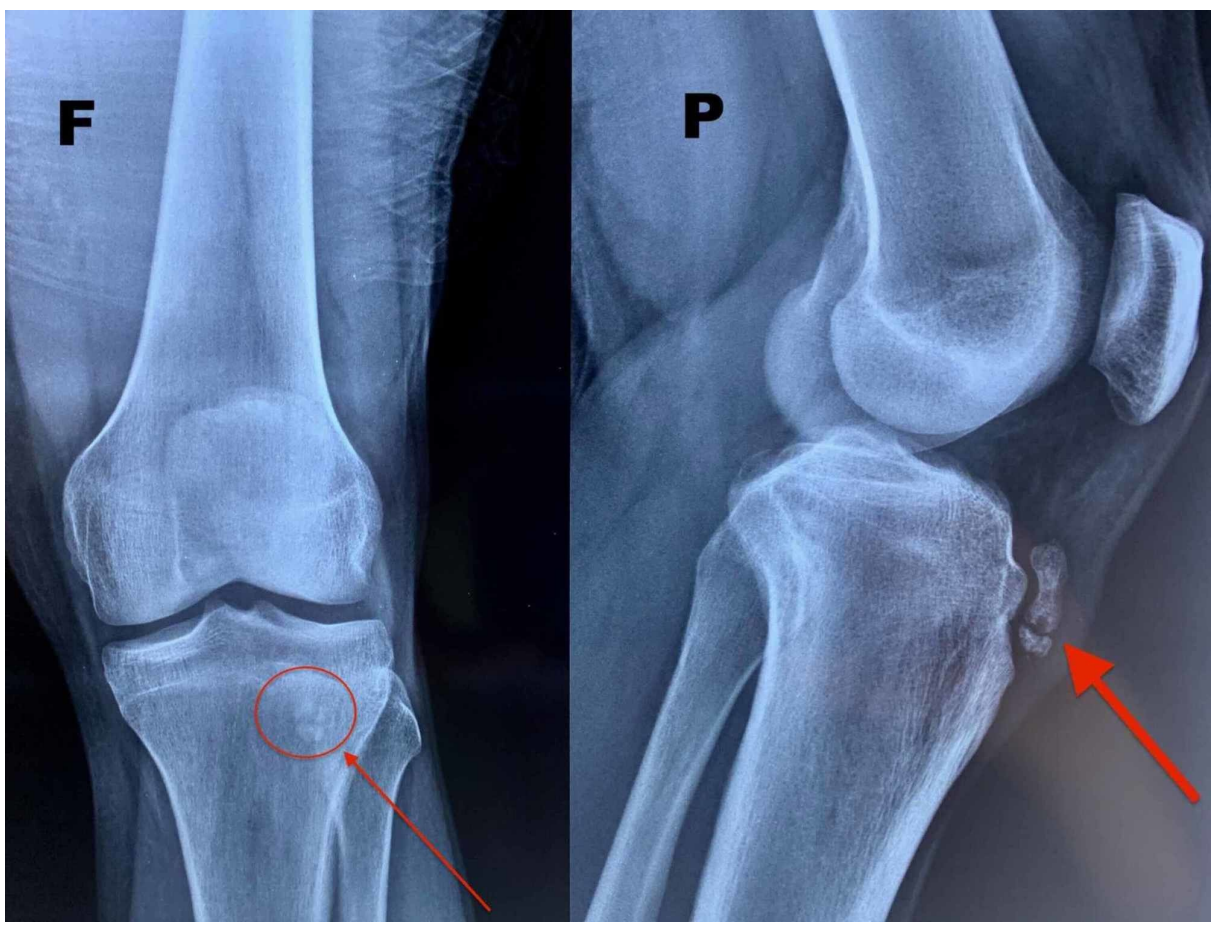

FIGURE 2: The $X$-ray in face $(F)$ and profile $(P)$ planes showing the ununited ossicle.

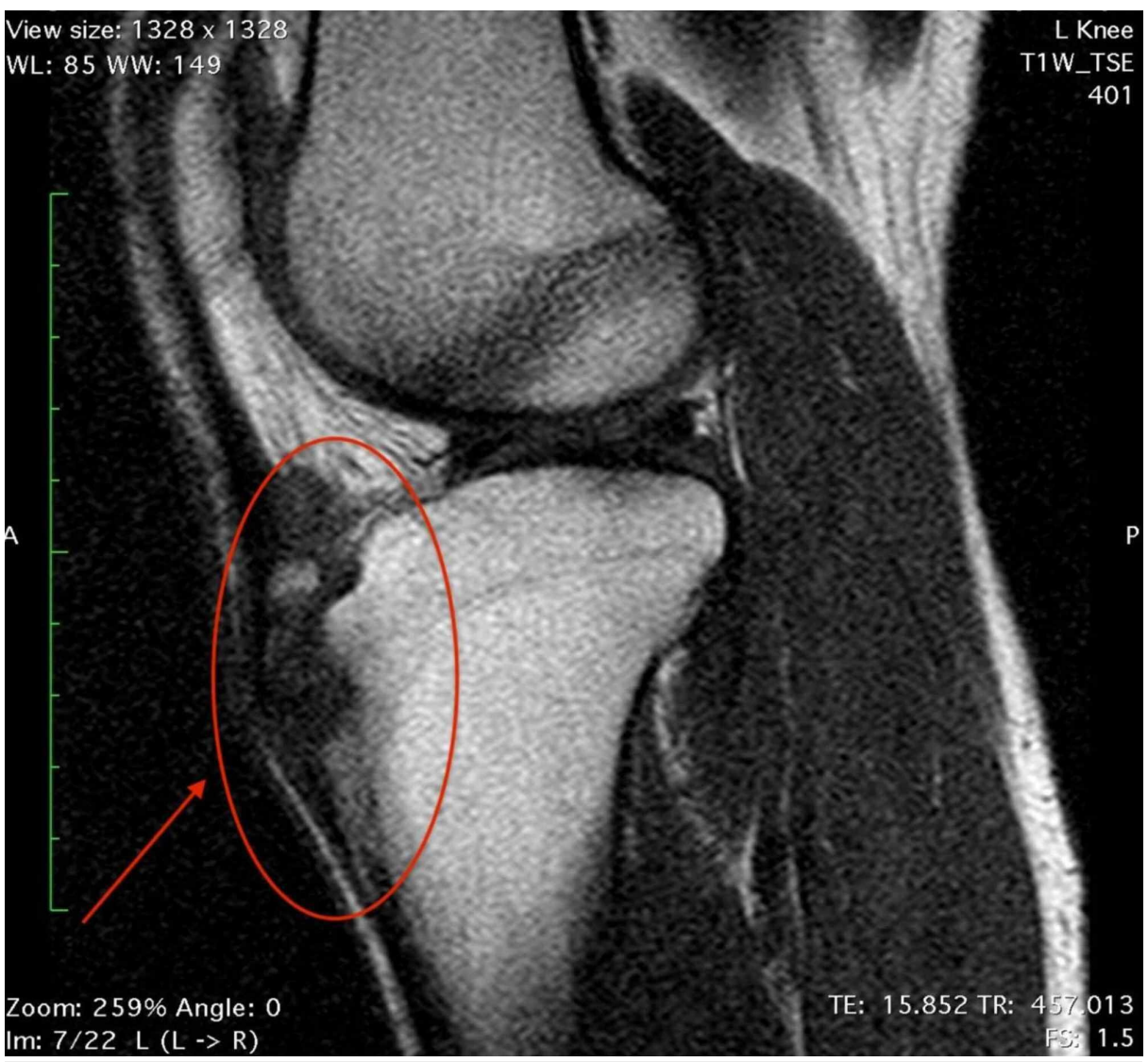

FIGURE 3: MRI scan showing the ossicle.

Diagnostic arthroscopy was performed using a low anterolateral portal close to patellar tendon (Figure 4). The intra-articular arthroscopic examination of the knee was unremarkable and no concomitant 


\section{Cureus}

abnormality was noticed. An anteromedial portal close to the patellar tendon was used and the infrapatellar fat pad beneath the patellar tendon was debrided with a motorized shaver. Localization of the ununited ossicle was performed by use of an 18-gauge needle that was advanced through the insertion site of the patellar tendon on the tibial tubercle under fluoroscopic control. The needle and the adjacent ossicle were visualized arthroscopically (Figure 5). In order for a better and adequate arthroscopic visualization to be achieved, a multidirectional arthroscope (ENDOCAMELEON ${ }^{\circledR}$ ARTHRO HOPKINS ${ }^{\circledR}$ Telescope) was used at $70^{\circ}$. The knee was extended in order to maximize the working space by relaxing the patellar tendon. The ossicle was identified, embedded in the patellar tendon and the dissection of the ossicle began with debridement of its proximal aspect with a radiofrequency device. Then the removal of the ossicle performed gradually with the use of a motorized shaver (Figure 5) and a motorized semi-hooded barrel burr (Figure 6). In order to achieve an even better approach to the ossicle, a second low anterolateral assisting portal was used. This was created below the first anterolateral portal, just lateral to the patellar tendon and to the ossicle (Figure 7). Fluoroscopic control was performed after removal of the ossicle to ensure no residue of bone (Figure 8 ).

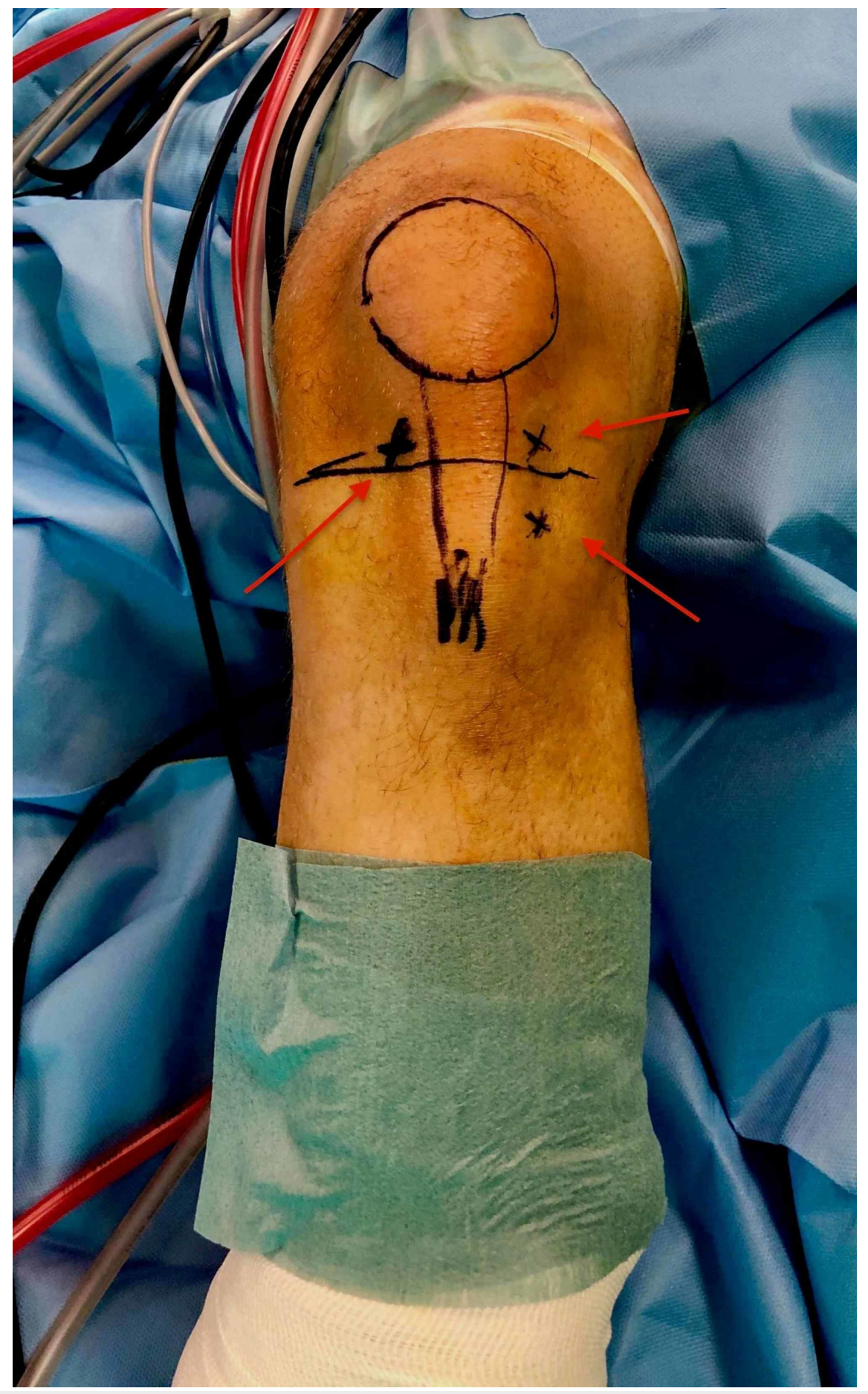

FIGURE 4: Marking of the arthroscopic portals in referral to the patellar, 


\section{Cureus}

the patellar tendon and the tibial tuberosity prominence.

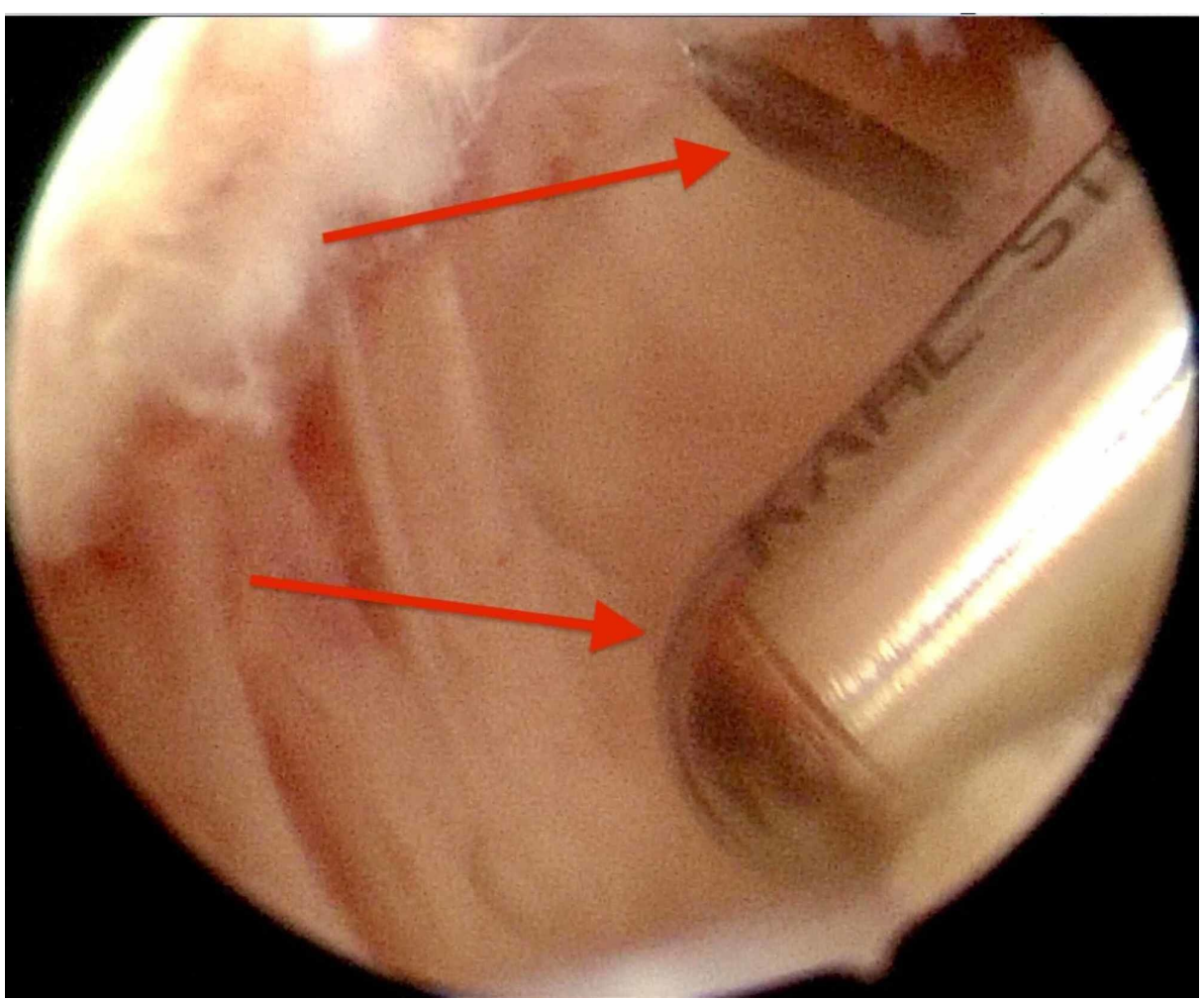

FIGURE 5: Visualization of the needle used as a guide. Also the saver working on the intra-articular side of the ossicle can be visualized.

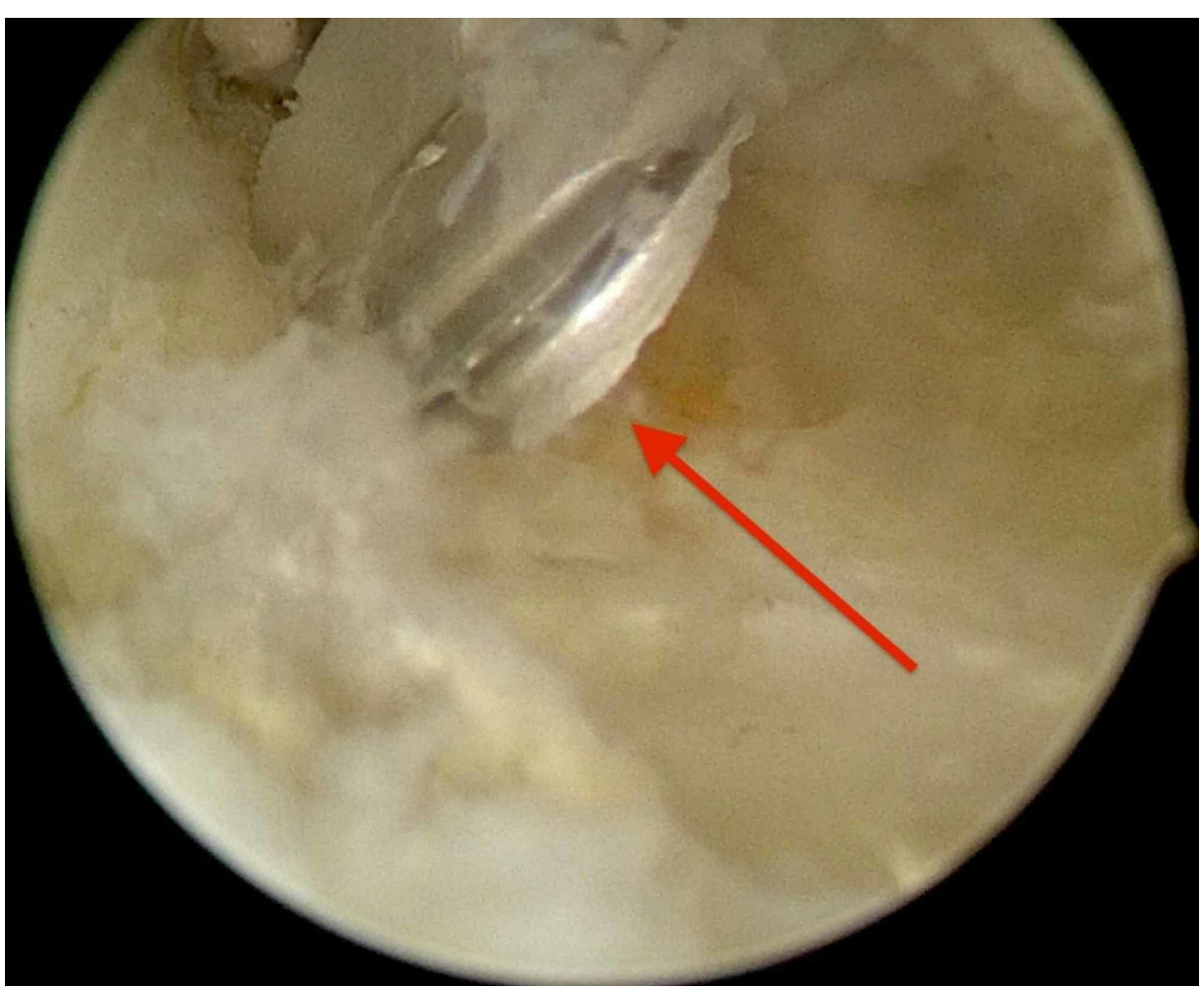

FIGURE 6: The motorized semi-hooded barrel burr used to resect most of the ossicle. 


\section{Cureus}

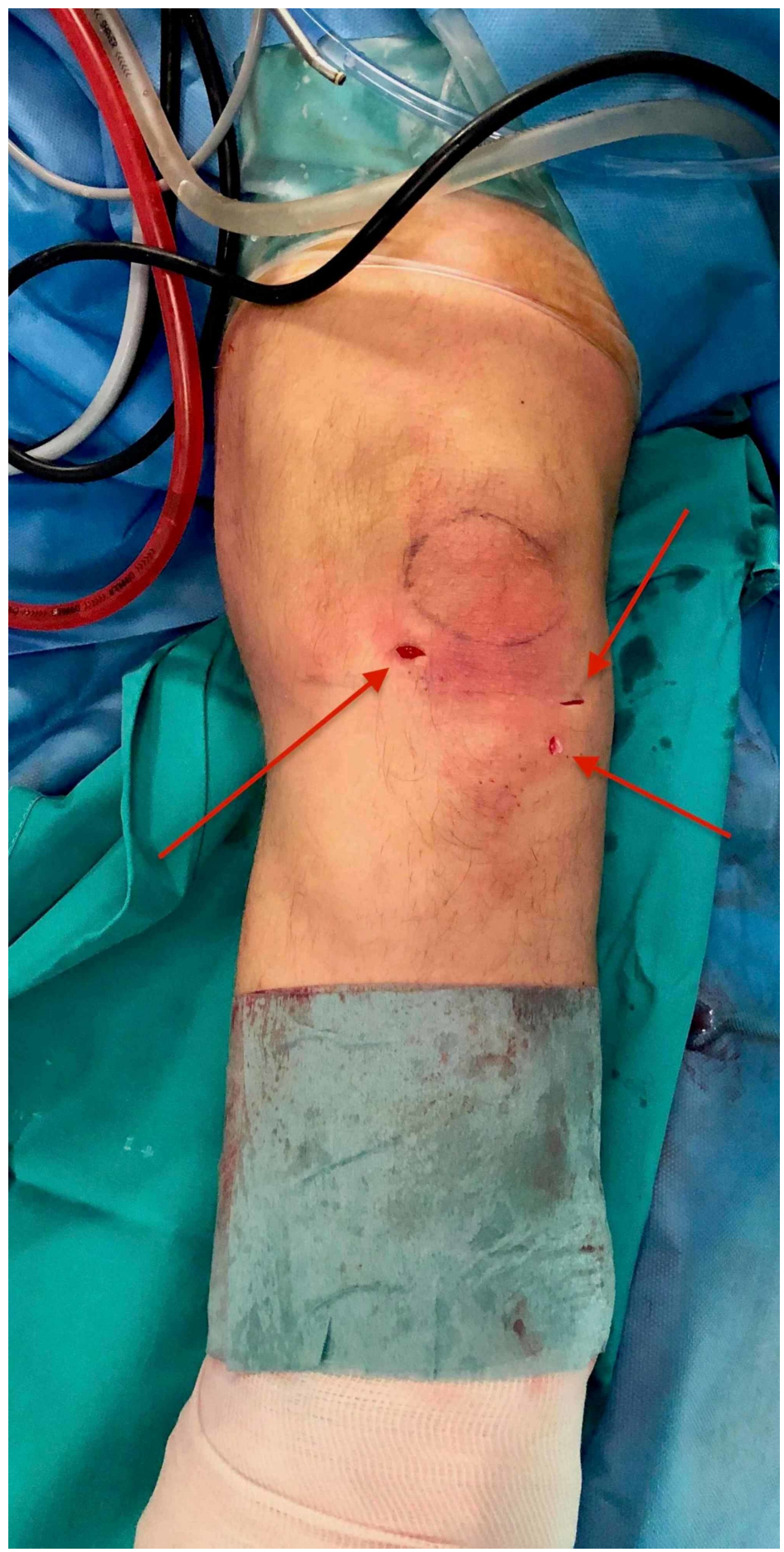

FIGURE 7: The incisions created and used for arthroscopy and removal of the lesion. 


\section{Cureus}

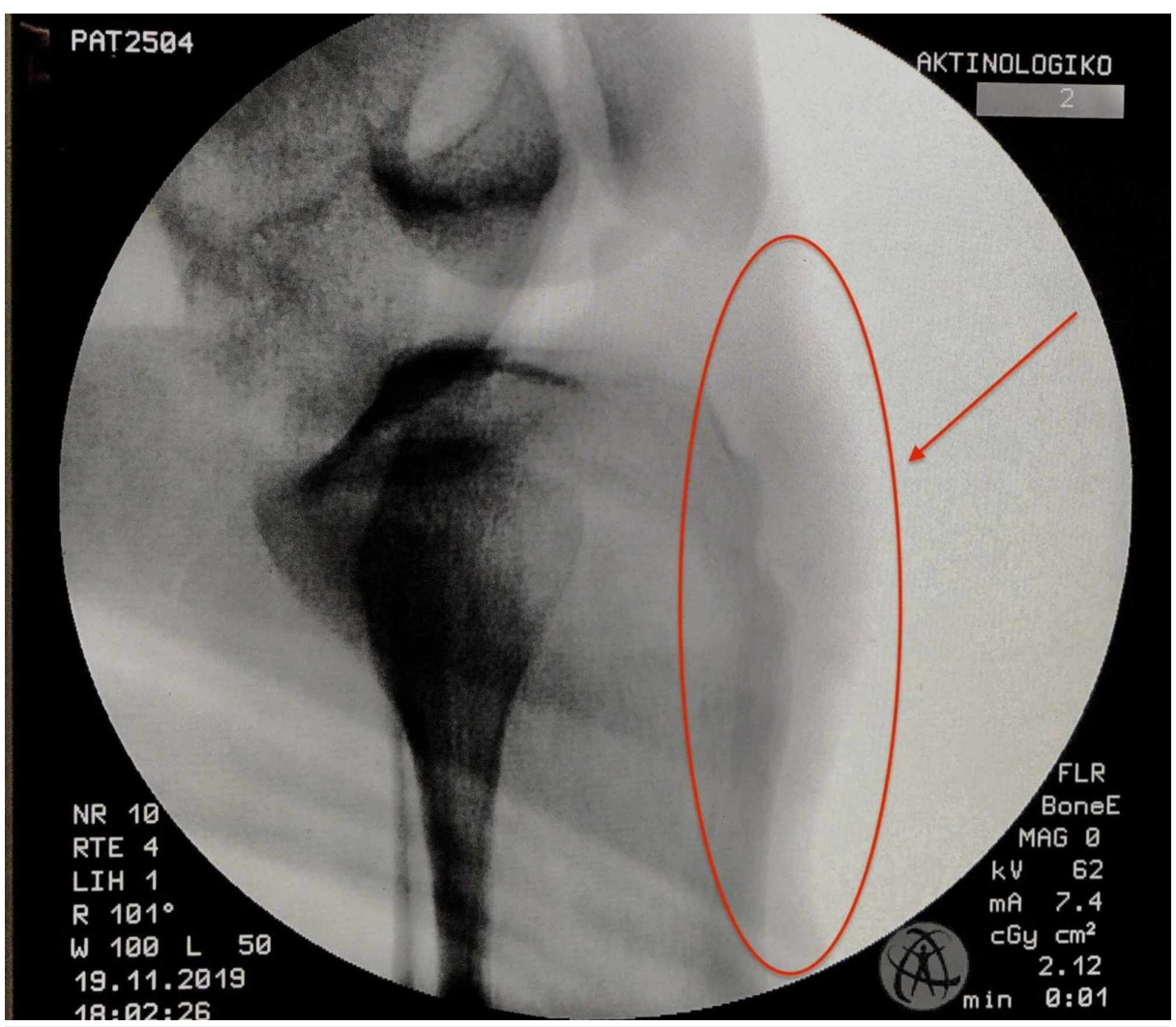

FIGURE 8: Fluoroscopic control intraoperatively after the ossicle removal.

Postoperatively, instructions for partial weight bearing and isometric flexion extension $0^{\circ}-90^{\circ}$ exercises for two weeks were given. After two weeks walking without crutches was allowed while no squatting for six weeks was suggested. After two months, the patient returned to sport activities without any restrictions and complaints. Postoperative X-ray showed minimal ossicle residual, and clinically there was no prominence (Figures 9, 10). 


\section{Cureus}

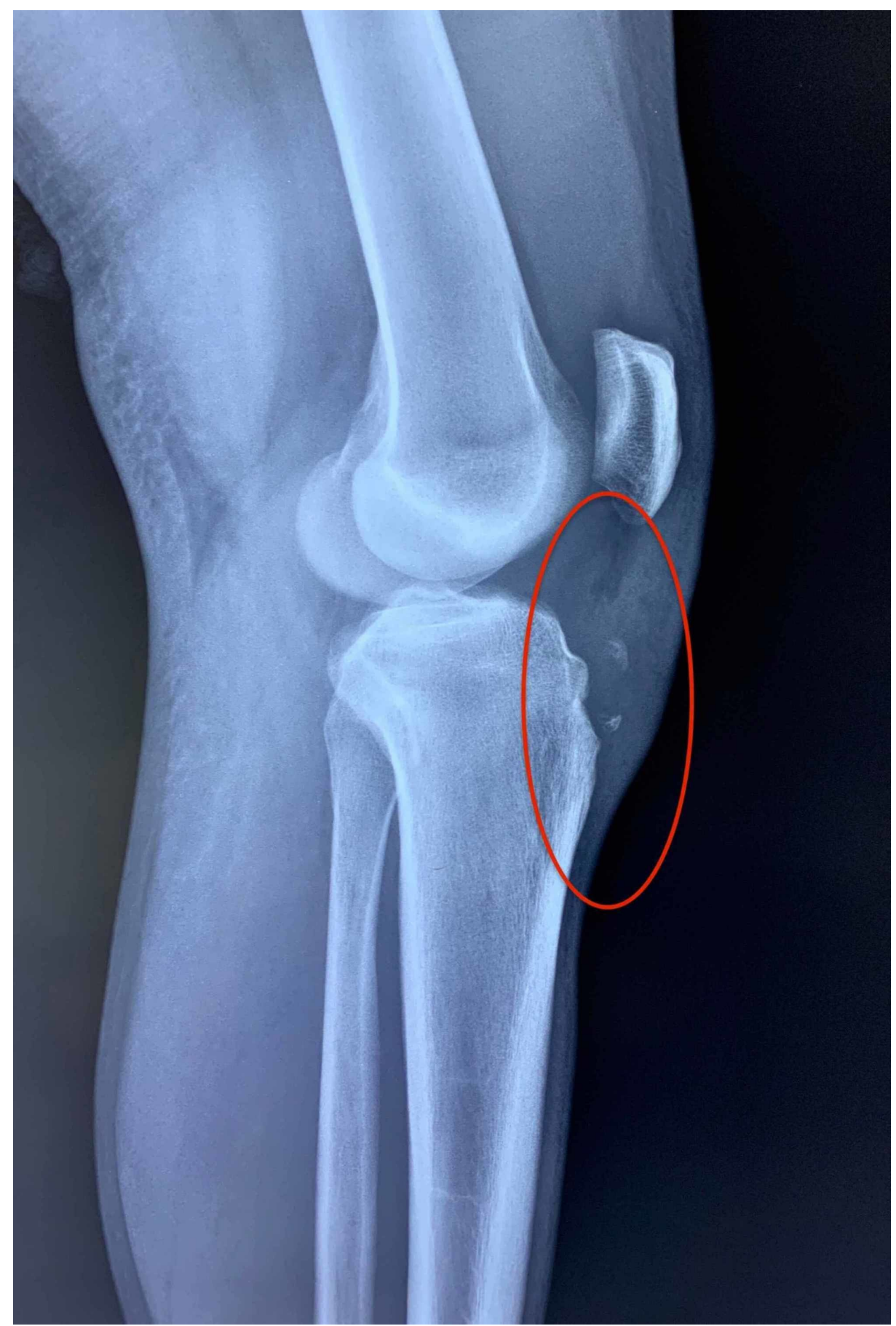

FIGURE 9: Postoperative X-ray. 


\section{Cureus}

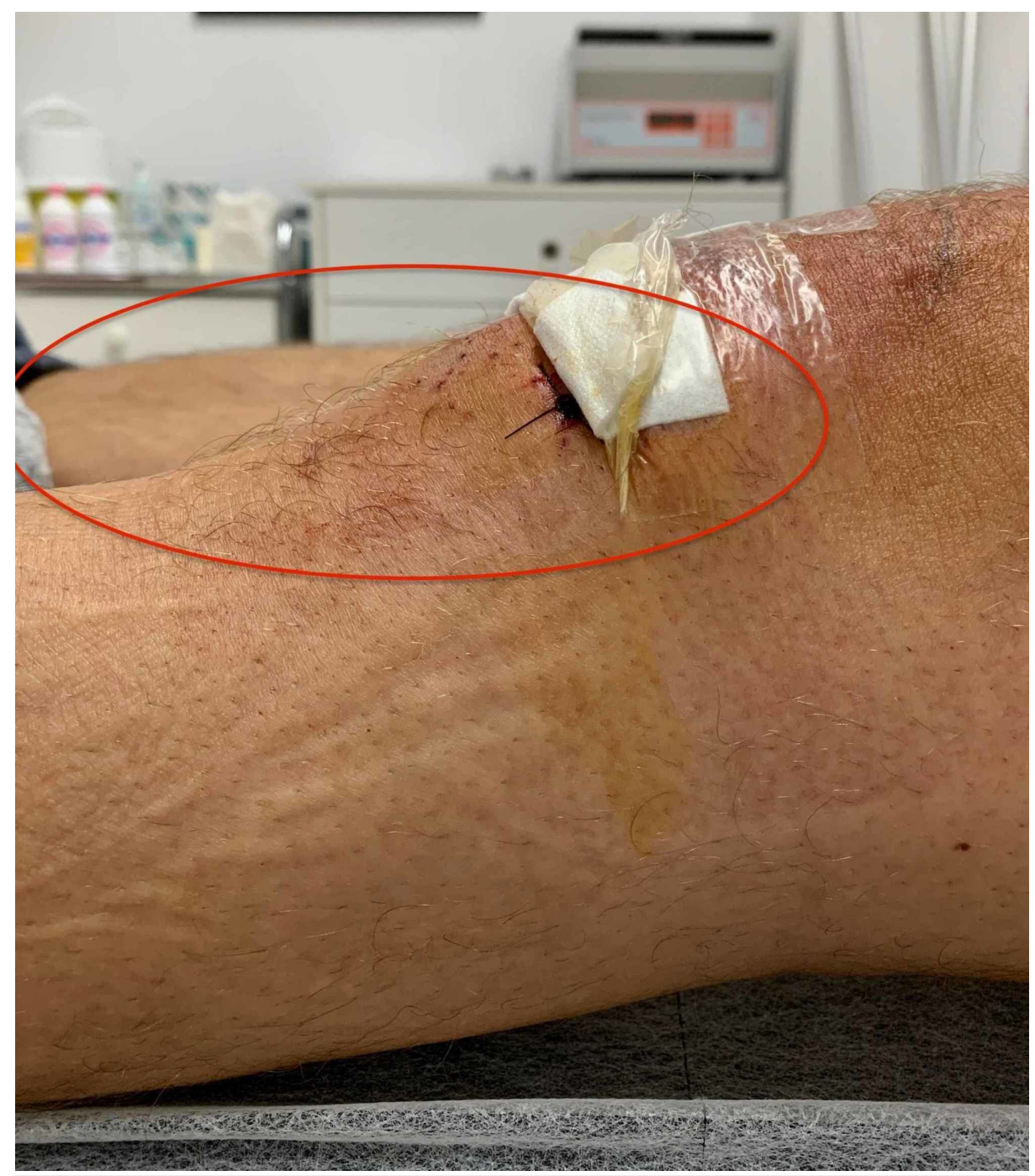

\section{FIGURE 10: No clinical prominence postoperatively.}

\section{Discussion}

Although the natural history of Osgood-Schlatter lesions is that most resolve and it is usually considered to be self-limited, some patients may still have some pain and prominence with kneeling [14]. Krause et al. reported that of 50 patients with an average of nine years follow-up, $60 \%$ were still unable to kneel without pain or discomfort and $24 \%$ had additional continuing symptoms [5]. Ross and Villard reported that athletes with a history of Osgood-Schlatter disease had higher levels of disability on both daily living and sports activity scales [15]. Conservative measures are regarded to be the treatment of choice in adolescents with Osgood-Schlatter disease. The goals of conservative treatment are to lessen the stress on the tibial tubercle and to reduce the tension in the quadriceps muscle [12].

However, if conservative treatment fails, operative treatment may be considered. There are surgical procedures that include drilling of the tubercle, removal of the loose fragments, autogenous bone peg insertion through the tubercle, tibial tuberosity excision, or sequestrectomy [12]. Furthermore, arthroscopic techniques for surgical treatment of Osgood-Schlatter disease have also been recommended as well as bursoscopic excision $[6,12,13]$. Arthroscopic procedure is a less invasive surgical modality while the patellar tendon is not violated and the patient avoids an incision directly over the patellar tendon that can cause pain with kneeling [6]. Bursoscopic excision allegedly has advantages over the classical arthroscopic approach because there is no need to perform an anterior interval release and there is no violation of the infrapatellar fat pad. Also a possible meniscus or intermeniscal ligament damage can be avoided $[6,13]$. However with this approach the working space might be limited and the reduce of the prominence of the tibial tuberosity might be inadequate.

\section{Conclusions}

In the case presented here, the use of multidirectional camera provided excellent view of the ossicle while its 
localization with a needle proved extremely helpful. The use of the assisting low anterolateral portal and of the motorized semi-hooded barrel burr provided an easy and rapid removal of the larger part of the bony lesion. We believe that the arthroscopic removal of an unresolved Osgood-Schlatter lesion showed excellent results and might be the most appropriate treatment for this condition.

\section{Additional Information \\ Disclosures}

Human subjects: Consent was obtained by all participants in this study. Conflicts of interest: In compliance with the ICMJE uniform disclosure form, all authors declare the following: Payment/services info: All authors have declared that no financial support was received from any organization for the submitted work. Financial relationships: All authors have declared that they have no financial relationships at present or within the previous three years with any organizations that might have an interest in the submitted work. Other relationships: All authors have declared that there are no other relationships or activities that could appear to have influenced the submitted work.

\section{References}

1. Osgood RB: Lesions of the tibial tubercle occurring during adolescence . Boston Med Surg J. 1903, 148:114117. 10.1056/NEJM190301291480502

2. Binazzi R, Felli L, Vaccari V, Borelli P: Surgical treatment of unresolved Osgood-Schlatter lesion. Clin Orthop Relat Res. 1993, 289:202-204.

3. Flowers MJ, Bhadreshwar DR: Tibial tuberosity excision for symptomatic Osgood-Schlatter disease . J Pediatr Orthop. 1995, 15:292-297. 10.1097/01241398-199505000-00005

4. Gholve PA, Scher DM, Khakharia S, Widmann RF, Green DW: Osgood Schlatter syndrome. Curr Opin Pediatr. 2007, 19:44-50. 10.1097/mop.0b013e328013dbea

5. Krause BL, Williams JP, Catterall A: Natural history of Osgood-Schlatter disease . J Pediatr Orthop. 1990, 10:65-68.

6. DeBerardino TM, Branstetter JG, Owens BD: Arthroscopic treatment of unresolved Osgood-Schlatter lesions. Arthroscopy. 2007, 23:1127. 10.1016/j.arthro.2006.12.004

7. Circi E, Atalay Y, Beyzadeoglu T: Treatment of Osgood-Schlatter disease: review of the literature . Musculoskelet Surg. 2017, 101:195-200. 10.1007/s12306-017-0479-7

8. El-Husseini TF, Abdelgawad AA: Results of surgical treatment of unresolved Osgood-Schlatter disease in adults. J Knee Surg. 2010, 23:103-108. 10.1055/s-0030-1267474

9. Nierenberg G, Falah M, Keren Y, Eidelman M: Surgical treatment of residual Osgood-Schlatter disease in young adults: role of the mobile osseous fragment. Orthopedics. 2011, 34:176. 10.3928/0147744720110124-07

10. Pihlajamaki HK, Mattila VM, Parviainen M, Kiuru MJ, Visuri TI: Long-term outcome after surgical treatment of unresolved Osgood-Schlatter disease in young men. J Bone Joint Surg Am. 2009, 91:2350-2358. 10.2106/JBJS.H.01796

11. Weiss JM, Jordan SS, Andersen JS, Lee BM, Kocher M: Surgical treatment of unresolved Osgood-Schlatter disease: ossicle resection with tibial tubercleplasty. J Pediatr Orthop. 2007, 27:844-847. 10.1097/BPO.0b013e318155849b

12. Beyzadeoglu T, Inan M, Bekler H, Altintas F: Arthroscopic excision of an ununited ossicle due to OsgoodSchlatter disease. Arthroscopy. 2008, 24:1081-1083. 10.1016/j.arthro.2007.03.010

13. Eun SS, Lee SA, Kumar R, Sul EJ, Lee SH, Ahn JH, Chang MJ: Direct bursoscopic ossicle resection in young and active patients with unresolved Osgood-Schlatter disease. Arthroscopy. 2015, 31:416-421. 10.1016/j.arthro.2014.08.031

14. Mital MA, Matza RA, Cohen J: The so-called unresolved Osgood-Schlatter lesion: a concept based on fifteen surgically treated lesions. J Bone Joint Surg Am. 1980, 62:732-739.

15. Ross MD, Villard D: Disability levels of college-aged men with a history of Osgood-Schlatter disease . J Strength Cond Res. 2003, 17:659-663. 10.1519/1533-4287(2003)017<0659:dlocmw>2.0.co;2 